\title{
Inpatient care of community-acquired pneumonia: The effect of antimicrobial guidelines on clinical outcomes and drug costs in Canadian teaching hospitals
}

\author{
Theodore K Marras MD FRCPC ${ }^{1}$, Linda Jamieson RN ${ }^{2}$, Charles K Chan MD FRCPC FCCP FACP 1
}

TK Marras, L Jamieson, CK Chan. Inpatient care of community-acquired pneumonia: The effect of antimicrobial guidelines on clinical outcomes and drug costs in Canadian teaching hospitals. Can Respir J 2004;11(2):131-137.

BACKGROUND: Evidence supporting antibiotic treatment guidelines and respiratory quinolones (RQs) in community-acquired pneumonia (CAP) is limited.

OBJECTIVE: To study associations among guideline adherence, specific antibiotics, clinical outcomes and antibiotic costs.

METHODS: A retrospective cohort study in three tertiary care university teaching hospitals in Toronto, Ontario, studying CAP inpatients between November 1997 and June 2000. The period encompassed 12 months when an early version of empirical antibiotic guidelines was used (early cohort) and 18 months when recent guidelines (including RQs) were used (recent cohort).

RESULTS: Six hundred ninety-eight cases of CAP were reviewed, and $91 \%$ were guideline adherent. In multivariable analyses, no association was observed between guideline adherence and mortality or duration of hospitalization. Guideline-adherent cases received fewer antibiotics in both cohorts and 0.9 days less of intravenous antibiotics $(\mathrm{P}=0.04)$ in the recent cohort. There was no significant difference in antibiotic cost according to guideline adherence, but recent cohort guideline-adherent cases had lower drug costs than early cohort guideline-adherent cases. Antibiotic selection was associated with illness severity and was mirrored by clinical outcomes, despite controlling for the pneumonia severity index (PSI). Treatment with anaerobic agents (odds ratio 2.7, $\mathrm{P}=0.001$ ) or cephalosporin plus macrolide (odds ratio 2.7, $\mathrm{P}=0.02$ ) was associated with higher mortality. Treatment with RQ monotherapy was associated with a 2.3 day shorter duration of intravenous therapy $(\mathrm{P}<0.0001)$ and a $\$ 19.19$ lower total antibiotic cost $(\mathrm{P}<0.0001)$.

CONCLUSION: Findings support empirical treatment guidelines for CAP and their recommendations regarding RQs. The association between mortality and anaerobic coverage or combination therapy may reflect prognostic information available at presentation but not captured by the PSI.

Key Words: Economics; Length of stay; Mortality; Outcomes; Pharmaceutical; Pneumonia; Practice guidelines
Les soins hospitaliers de la pneumonie non nosocomiale : L'effet des lignes directrices antimicrobiennes sur les issues cliniques et le coût des médicaments dans les hôpitaux d'enseignement canadiens

HISTORIQUE : Les données probantes à l'appui des lignes directrices sur l'antibiothérapie et les quinolones respiratoires (QR) en cas de pneumonie non nosocomiale (PNN) sont limitées.

OBJECTIF : Étudier les associations entre le respect des lignes directrices, des antibiotiques précis, les issues cliniques et le coût des antibiotiques. MÉTHODOLOGIE : Une étude de cohorte rétrospective a été menée dans trois hôpitaux d'enseignement universitaire de soins tertiaires de Toronto, en Ontario, portant sur des patients hospitalisés atteints de PNN entre novembre 1997 et juin 2000. La période incluait 12 mois au cours desquels une première version des lignes directrices sur les antibiotiques empiriques était utilisée (première cohorte) et 18 mois au cours desquels les lignes directrices récentes (y compris les $Q R$ ) étaient utilisées (cohorte récente).

RÉSULTATS : Six cent quatre-vingt-dix huit cas de PNN ont été examinés, et $91 \%$ respectaient les lignes directrices. Dans les analyses multivariées, on ne remarquait aucune association entre le respect des lignes directrices et la mortalité ou la durée d'hospitalisation. Les cas respectant les lignes directrices recevaient moins d'antibiotiques dans les deux cohortes, et la cohorte récente recevait des antibiotiques intraveineux pendant 0,9 jour $(\mathrm{P}=0,04)$ de moins. On ne remarquait aucune différence significative du coût des antibiotiques d'après le respect des lignes directrices, mais le coût des médicaments des cas de la cohorte récente respectant les lignes directrices était moins élevé que celui de la première cohorte respectant les lignes directrices. La sélection d'antibiotiques s'associait à la gravité de la maladie et était reflétée par les issues cliniques, malgré un contrôle de l'indice de gravité de la pneumonie (IGP). Le traitement par des agents anaérobiques (risque relatif de $2,7, \mathrm{P}=0,001$ ) ou par une céphalosporine associée à un macrolide (risque relatif de $2,7, \mathrm{P}=0,02$ ) s'associait à une mortalité plus élevée. Une monothérapie aux $\mathrm{QR}$ s'associait à une réduction de 2,3 jours du traitement intraveineux $(\mathrm{P}<0,0001)$ et à une baisse du coût total des antibiotiques de $19,19 \$(\mathrm{P}<0,0001)$.

CONCLUSION : Les observations appuient les lignes directrices de traitement empirique de la PNN et les recommandations en découlant à l'égard des QR. Le lien entre la mortalité et la couverture anaérobique ou la thérapie d'association peut refléter les renseignements pronostiques disponibles à la présentation, mais non décelés au moyen de l'IGP.

$30 / 1000$ people over the age of 75 years $(1,2)$. It has been estimated that the bulk of treatment costs relate to inpatient care $(3,4)$, which may represent 60,000 hospitalizations and more than $\$ 100$ million annually in Canada (5). Among patients hospitalized with CAP, mortality ranges from $8 \%$ to $16 \%(6-8)$ and have been reported at 12/1000 patients/year; elderly people are particularly susceptible, with an annual incidence of over

${ }^{1}$ Department of Medicine, University of Toronto; ${ }^{2}$ Division of Respirology, University Health Network, Toronto Ontario

Correspondence: Dr TK Marras, The Asthma Centre, Toronto Western Hospital, 4th Floor, Edith Cavell Wing, 399 Bathurst Street, Toronto,

Ontario M5T 2S8. Telephone 415-206-3512 or 415-206-8313, fax 415-695-1551, e-mail ted.marras@utoronto.ca 
varies predictably with individual clinical characteristics (6). Clinical and radiographic features are not consistently reliable in determining the causative microorganism (9-13), necessitating initial empirical antimicrobial therapy. Selection of initial therapy may be assisted by empirical antibacterial treatment guidelines (14-19). Recent guidelines recommend respiratory quinolones (RQs) - levofloxacin, gatifloxacin and moxifloxacin - in several settings $(15,16,18)$. These agents provide an appealing choice in the therapy of CAP because they offer effective single-agent coverage for Streptococcus pneumoniae, most relevant Gram-negative organisms and atypical pathogens.

Prospective trials assessing the impact of guideline adherence on clinical outcomes have not been performed, but observational studies of previous guidelines for the treatment of CAP have generally not shown that adherence produced significant improvements in clinical outcomes $(8,20)$. A more recent study found a lower mortality rate in elderly inpatients treated with regimens that included coverage for atypical organisms (21), but use of the more recent guidelines $(15,16,18)$, which recommend RQs, has not been well studied. A study of a critical pathway, which included the RQ levofloxacin and multiple clinical interventions, found similar clinical outcomes and a reduction in institutional resource utilization in the intervention institutions (22). Given the study design, it was difficult to distinguish the effects of the antibiotic therapy from the clinical interventions included in the critical pathway. Authors Marras and Chan found guideline utilization to be high in a previous review at their institution (8), but have little information on adherence to more recent guidelines.

We performed a retrospective cohort study to assess several issues. First, we studied the implementation of antimicrobial guidelines, comparing secular periods before and after their revision. Second, we searched for associations between guideline adherence and clinical outcomes or antimicrobial costs in both the early and recent cohorts. Third, we compared outcomes between guideline-adherent cases in the early and recent cohorts. Fourth, we assessed differences in outcomes between patients treated with various empirical antimicrobials.

\section{PATIENTS AND METHODS}

\section{Patients and study site}

Charts of potential cases were identified retrospectively by International Coding of Diagnosis (Ninth Revision) classification, including codes for pneumonia and potentially overlapping diagnostic codes, including chronic bronchitis, emphysema and asthma. A stratified, random sample of potential cases, admitted to our institutions between November 1997 and June 2000, was reviewed. Based on resource limitations, our review was limited to $70 \%$ of cases admitted during each study era (defined below). Eligible cases required at least one symptom (dyspnea, cough, fever), a consistent radiograph and antibiotic treatment for CAP. Exclusion criteria were infection with human immunodeficiency virus or being otherwise immune suppressed, known or suspected tuberculosis, discharge from an acute care hospital within 10 days before study admission and presence of a concurrent nonrespiratory infection requiring antibacterial therapy.

The study sites were the Toronto General Hospital, Toronto Western Hospital and Mount Sinai Hospital (tertiary care, teaching hospitals affiliated with the University of Toronto, Toronto,
Ontario). All three sites have general internal medicine (GIM) clinical teaching units into which patients with CAP are generally admitted and managed. The source of referrals is almost exclusively from the emergency department (ED), to which patients either self-refer or are sent by primary care practitioners. If the ED physician decides that the patient requires admission or to see a specialist, a consultation from the GIM service is obtained. The GIM team makes the admission decision and all inpatient care decisions.

The study period (November 1997 to June 2000) was divided into early and recent cohort periods, defined by the contemporary version of antibiotic guidelines endorsed at the University of Toronto. The early cohort period was from November 1997 to October 1998 (1993 Canadian Thoracic and Infectious Diseases Societies' guidelines [23]), and the recent cohort period was from November 1998 to June 2000 (1998 Infectious Diseases Society of America [IDSA] guidelines [24]). The study period began one year before our institutions endorsed the first widely publicized CAP guidelines recommending RQs (24), through the revision of institutional recommendations and addition of a RQ (levofloxacin) to the formularies. The duration of the study period was selected to capture a significant number of CAP cases treated according to both the early and recent guidelines. The appropriate institutional research ethics review boards approved the protocol.

\section{Data collection and management}

Charts were screened by one of two reviewers, who recorded the data of interest for all eligible patients. Length of stay (LOS) in the hospital was defined as the number of calendar days from presentation to the ED to discharge (inclusive), to a maximum of 42 days. In-hospital mortality was defined as inpatient death within 42 days of admission. Consistent with others, LOS and mortality were censored at 42 days, assuming that events after 42 days were unlikely to be directly related to the CAP episode (22). Classification of guideline compliance was based on the version of CAP guidelines contemporary to the study period (1993 Canadian Thoracic and Infectious Diseases Societies' [23] guidelines for the early period and 1998 IDSA guidelines [24] for the recent period). The empirical regimen was defined as the first regimen prescribed, or in the case of an early medication change, the regimen prescribed within the first $24 \mathrm{~h}$ and continued beyond that $24 \mathrm{~h}$ period. A regimen was defined as providing anaerobic coverage if it contained either metronidazole or clindamycin. The time to first antibiotic dose was defined as the time from initial presentation to the ED to the time of first dose administration. The total number of antibiotics was counted to include oral and intravenous (IV) preparations of the same drug only once. For example, in a patient who received IV followed by oral cefuroxime, one antibiotic was counted. Antibiotic costs were measured in Canadian dollars as hospital drug acquisition prices, as of January 2000, not including nursing time, IV equipment or preparation costs.

Information from medical records was entered directly into an electronic database, designed in Microsoft Access/Office 2000 (Microsoft Corporation, USA). Two of the investigators periodically reviewed the entire database for inconsistencies, and when identified, they were investigated and corrected by repeated medical record review. 


\section{Statistical analysis}

Baseline characteristics and outcomes are described as one large group and divided by era and guideline adherence. Continuous data are expressed as mean $( \pm$ SD) for normal distributions or median (plus quartiles) and compared with $t$ tests or MannWhitney $U$ tests. Baseline categorical data were compared with $\chi^{2}$ tests (Yates corrected for $2 \times 2$ tables). Differences between empirical antimicrobial regimens were analyzed using $\chi^{2}$ tests for categorical data and analyses of variance or Kruskall-Wallis tests for continuous data. Multivariable analyses consisted of linear and logistical regression for continuous and binary outcomes, respectively. Non-normally distributed explanatory variables were transformed with the natural logarithm. All multivariable analyses were controlled for pneumonia severity index (PSI) score (6) and study site, and used backward selection procedures. To avoid overfitting, fewer than 10 explanatory variables per number of subjects or number of outcomes were introduced into automated selection procedures. No formal power calculations were performed.

Given that the PSI was derived for the prediction of mortality, multivariable analyses for LOS were also controlled for age, sex, long-term care residence, diabetes, congestive heart failure, cancer, or chronic lung, liver or renal disease. Morality was also controlled for in the analysis of LOS, drug costs and duration of IV therapy (high early mortality could result in shorter LOS, lower costs and shorter duration of IV therapy). All statistical analyses were performed using SAS version 8.0 (SAS Institute, USA).

\section{RESULTS}

Of the 2324 potentially eligible cases, approximately $70 \%$ from each era were reviewed (Figure 1). Of the 1682 (72\%) potentially eligible cases reviewed, 698 eligible cases were identified and reviewed in full. Of the 984 ineligible cases, 416 (42\%) were due to recent hospital discharge, 342 (35\%) were due to coexisting infection, 108 (11\%) did not meet either symptomatic or radiographic criteria for CAP and 118 (12\%) were immune suppressed. Baseline and outcome data classified by secular period and guideline adherence are presented in Tables 1 and 2, respectively. Overall, the patients were elderly (median age 78 years) and had high illness severity (mean PSI score 116,

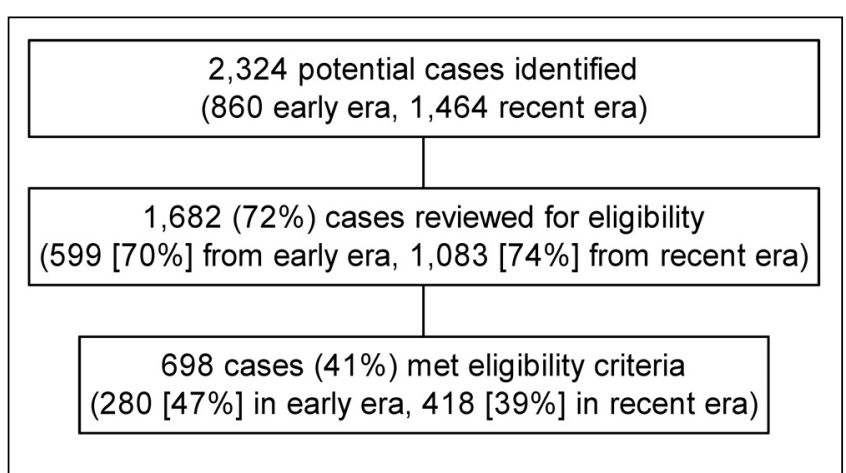

Figure 1) Case identification and selection. Approximately 70\% of all cases identified in each era were randomly selected for review

risk class 4$)$. Fifty-five patients ( $8 \%$ ) were admitted to the intensive care unit at some time during hospitalization, while 40 patients $(6 \%)$ were admitted to the intensive care unit within the first $24 \mathrm{~h}$ after admission. Median LOS was seven days, and in-hospital mortality was 9.2\%.

Analyses by guidelines

Overall, 636 cases (91\%) were treated according to guidelines, with a nonsignificant increase in adherence between the early and recent periods ( $89 \%$ to $92 \%, \mathrm{P}=0.20$ ). Comparing guidelineadherent versus guideline-discordant cases, multivariable analysis found no significant association with mortality in the early or recent cohorts. Also, in guidelines-adherent patients, there was no difference in mortality between early and recent guidelines cohorts. No significant differences in LOS were observed in multivariable analyses comparing guideline-adherent with guideline-discordant cases in early or recent cohorts or between early and recent versions of guidelines.

In multivariable analysis, guideline adherence was associated with 0.9 days fewer of IV antibiotics (95\% CI 0.03 to 1.52 , $\mathrm{P}=0.04)$ in the recent era. Recent cohort guideline-adherent cases had 1.8 days fewer of IV antibiotics (95\% CI 1.5 to 2.1, $\mathrm{P}<0.0001)$ than early cohort guideline-adherent cases.

\section{TABLE 1}

Baseline patient data in a study examining the effect of antimicrobial guidelines on clinical outcomes and drug costs in Canadian teaching hospitals

\begin{tabular}{|c|c|c|c|c|c|c|c|c|}
\hline & \multirow[b]{2}{*}{$\begin{array}{l}\text { Overall } \\
(n=698)\end{array}$} & \multicolumn{3}{|c|}{ Early cohort $(\mathrm{n}=\mathbf{2 8 0})$} & \multicolumn{3}{|c|}{ Recent cohort $(n=418)$} & \multirow[b]{2}{*}{$P^{\dagger}$} \\
\hline & & $\begin{array}{l}\text { Guideline- } \\
\text { adherent } \\
(n=250)\end{array}$ & $\begin{array}{l}\text { Guideline- } \\
\text { discordant } \\
(n=30)\end{array}$ & $\mathbf{P}^{*}$ & $\begin{array}{l}\text { Guideline- } \\
\text { adherent } \\
(\mathrm{n}=386)\end{array}$ & $\begin{array}{l}\text { Guideline- } \\
\text { discordant } \\
(n=32)\end{array}$ & $\mathbf{P}^{*}$ & \\
\hline Age in years (median [quartiles]) & $78(70,84)$ & $78(71,86)$ & $72(67,78)$ & 0.005 & $78(71,84)$ & $72(61,79)$ & 0.007 & 0.12 \\
\hline Female sex (n [\%]) & $272(39)$ & $106(42)$ & $14(47)$ & 0.8 & $141(37)$ & $11(34)$ & 0.99 & 0.14 \\
\hline LTC residence $(\mathrm{n}[\%])$ & $156(22)$ & $55(22)$ & $6(20)$ & 0.99 & $88(23)$ & $7(22)$ & 1 & 0.89 \\
\hline $\mathrm{PSI}{ }^{\ddagger}$ score $($ mean $\pm \mathrm{SD})$ & $116 \pm 37$ & $115 \pm 37$ & $106 \pm 31$ & 0.2 & $118 \pm 36$ & $101 \pm 41$ & 0.02 & 0.19 \\
\hline \multicolumn{9}{|l|}{ PSI class distribution ( $\mathrm{n}[\%]$ ) } \\
\hline $1-3$ & $179(26)$ & $71(28)$ & $12(40)$ & 0.24 & $82(21)$ & $14(44)$ & 0.002 & 0.12 \\
\hline 4 & $301(43)$ & $102(41)$ & $11(37)$ & & $175(46)$ & $12(38)$ & & \\
\hline 5 & $218(31)$ & $77(31)$ & $7(23)$ & & $128(33)$ & $6(19)$ & & \\
\hline $\begin{array}{l}\text { Time to first antibiotic dose }(\mathrm{h}) \\
\quad \text { (median [quartiles]) }\end{array}$ & $4(2,10)$ & $5(3,9)$ & $5(4,12)$ & 0.5 & $4(2,10)$ & $6(3,16)$ & 0.08 & 0.08 \\
\hline
\end{tabular}

*Comparison between guideline-adherent and guideline-discordant cases; ${ }^{\dagger}$ Comparison between guideline-adherent cases in early versus recent cohorts; $\ddagger$ Pneumonia severity index (PSI) (6). LTC Long-term care 


\begin{tabular}{|c|c|c|c|c|c|c|c|c|}
\hline & \multirow[b]{2}{*}{$\begin{array}{l}\text { Overall } \\
(n=698)\end{array}$} & \multicolumn{3}{|c|}{ Early cohort $(n=280)$} & \multicolumn{3}{|c|}{ Recent cohort ( $n=418)$} & \multirow[b]{2}{*}{$\mathbf{P}^{\dagger}$} \\
\hline & & $\begin{array}{l}\text { Guideline- } \\
\text { adherent } \\
(n=250)\end{array}$ & $\begin{array}{l}\text { Guideline- } \\
\text { discordant } \\
(n=30)\end{array}$ & $\mathbf{P}^{*}$ & $\begin{array}{l}\text { Guideline- } \\
\text { adherent } \\
(n=386)\end{array}$ & $\begin{array}{l}\text { Guideline- } \\
\text { discordant } \\
(n=32)\end{array}$ & $\mathbf{P}^{*}$ & \\
\hline $\begin{array}{l}\text { Duration intravenous therapy in days } \\
\text { (median [quartiles]) }\end{array}$ & $3(1,5)$ & $4(3,6)$ & $3(1,6)$ & 0.18 & $1(1,4)$ & $3(0.5,6)$ & 0.26 & $<0.0001$ \\
\hline Antibiotic cost (median [quartiles]) & $\begin{array}{c}\$ 71.00 \\
\$ 36.42, \$ 130.08)\end{array}$ & $\begin{array}{c}\$ 84.00 \\
(\$ 50.01, \$ 148.68)\end{array}$ & $\begin{array}{c}\$ 91.18 \\
(\$ 49.23, \$ 185.44)\end{array}$ & 0.64 & $\begin{array}{c}\$ 63.00 \\
(\$ 30.58, \$ 107.96)\end{array}$ & $\begin{array}{c}\$ 85.56 \\
(\$ 29.42, \$ 174.82)\end{array}$ & 0.23 & $<0.0001$ \\
\hline Length of stay in days (median [quartiles]) & $7(5,10)$ & $7(5,10)$ & $7(5,10)$ & 0.5 & $7(5,11)$ & $7(5,12)$ & 0.58 & 0.71 \\
\hline Mortality (n [\%]) & $64(9.2)$ & $26(10.4)$ & 0 & 0.09 & $34(8.8)$ & $4(12.5)$ & 0.52 & 0.59 \\
\hline \multicolumn{9}{|l|}{ Number of empirical antibiotics (\%) } \\
\hline $\begin{array}{l}1 \\
\geq 2\end{array}$ & $\begin{array}{l}525(75) \\
173(25)\end{array}$ & $\begin{array}{r}169(68) \\
81(32)\end{array}$ & $\begin{array}{l}10(33) \\
20(67)\end{array}$ & 0.0005 & $\begin{array}{r}327(85) \\
59(15)\end{array}$ & $\begin{array}{l}19(59) \\
13(41)\end{array}$ & 0.0007 & $<0.0001$ \\
\hline \multicolumn{9}{|l|}{ Total number of antibiotics (\%) } \\
\hline 1 & $347(50)$ & $115(46)$ & $1(3)$ & $<0.0001$ & $226(59)$ & $5(16)$ & $<0.0001$ & 0.008 \\
\hline 2 & $195(28)$ & $78(31)$ & $11(37)$ & & $93(24)$ & $13(41)$ & & \\
\hline$\geq 3$ & $156(22)$ & $57(23)$ & $18(60)$ & & $67(17)$ & $14(43)$ & & \\
\hline
\end{tabular}

${ }^{*}$ Comparison between guideline-adherent and guideline-discordant cases; ${ }^{\dagger}$ Comparison of guideline-adherent cases in early and recent cohorts

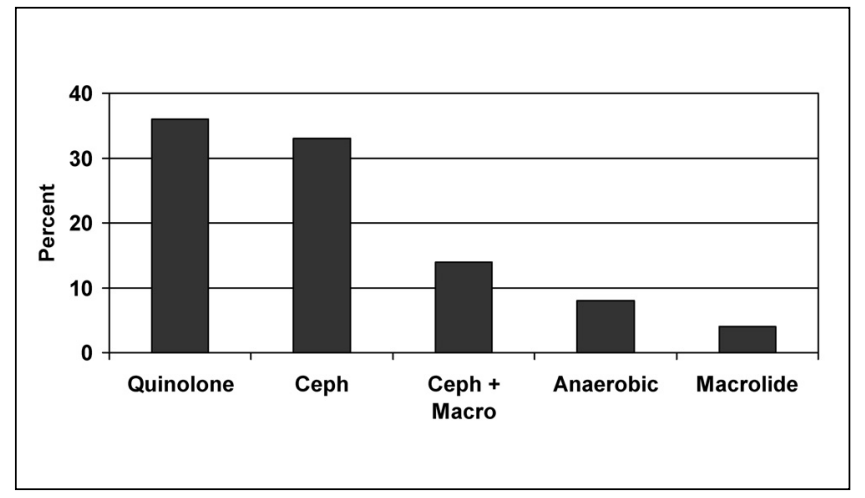

Figure 2) Initial empirical antibiotics for all cases expressed as the per cent of all patients receiving each empiric antibiotic regimen. Quinolone is quinolone monotherapy (levofloxacin in 98\%); Ceph is cephalosporin monotherapy (second-generation cephalosporin [cefuroxime] in over 90\%); Ceph + macrolide is cephalosporin plus macrolide therapy; Anaerobic is regimens that included agents with significant anaerobic activity; Macrolide is macrolide monotherapy

Analogous multivariable analyses of antibiotic costs found a $\$ 5.70$ lower cost $(95 \%$ CI 3.20 to $7.84, \mathrm{P}<0.0001)$ in recent versus early cohort guideline-adherent cases.

\section{Analysis by empirical antibiotic regimen}

The most commonly-selected antibiotic regimens are shown in Figure 2. Quinolone monotherapy (levofloxacin in 98\%) and cephalosporin monotherapy (cefuroxime in over 90\%) were the two most common regimens in the recent and early cohorts, respectively. Baseline clinical characteristics and univariate outcome analyses classified by empirical antibiotics are presented in Tables 3 and 4. On average, patients receiving empirical cephalosporin plus a macrolide or anaerobic coverage had higher PSI scores, while patients treated with empirical macrolide monotherapy had lower PSI scores (Table 3). Univariate analyses of clinical outcomes were consistent with the differences in PSI scores. Patients receiving empirical cephalosporin plus a macrolide or anaerobic coverage had longer LOSs and higher mortality, while patients treated with empirical macrolide monotherapy had shorter LOSs and lower mortality (Table 4).

To assess the specific impact of different empirical antibiotic regimens, multivariable modelling of mortality, LOS, duration of IV therapy and antibiotic cost was performed (Table 5). Despite controlling for PSI, time to initial antibiotic dose and study site, patients receiving empirical cephalosporin plus a macrolide or coverage for anaerobes had significantly higher mortality. Both of these groups also had higher antibiotic costs. Patients treated with empirical macrolide monotherapy had a shorter LOS and duration of IV therapy, as well as lower antibiotic cost. Patients treated with quinolone monotherapy had a shorter duration of IV antibiotic therapy and lower antibiotic costs. Toxicities necessitating a change in therapy were uncommon. This occurred in two patients treated with levofloxacin and three patients treated with cephalosporinbased regimens.

\section{DISCUSSION}

We consider our experience with the inpatient treatment of CAP to be generalizable to similar contemporary populations in other Canadian centres. The cohort was composed of elderly patients (mean age 78 years) with a high risk of mortality (mean PSI score 116, class 4), reflecting the aging patient population and high illness acuity seen in patients admitted urgently to acute care hospitals. Our broad definition of CAP allows for the results to be generalizable by taking into account the diagnostic uncertainty in patients with high rates of cardiopulmonary disease presenting with acute chest symptoms. The finding of only $61 \%$ male patients in our cohort could reflect a bias in case ascertainment; however, a similar male predominance has been reported in other Canadian studies $(7,25)$.

Guideline compliance was high in our study, with over $90 \%$ of cases treated according to recommendations. Despite a change in guidelines during the study period, we observed a nonsignificant increase in compliance, from $89 \%$ to $92 \%$. The high rates of adherence likely relate to the institutional 
TABLE 3

Baseline clinical characteristics classified by empirical antibiotic therapy

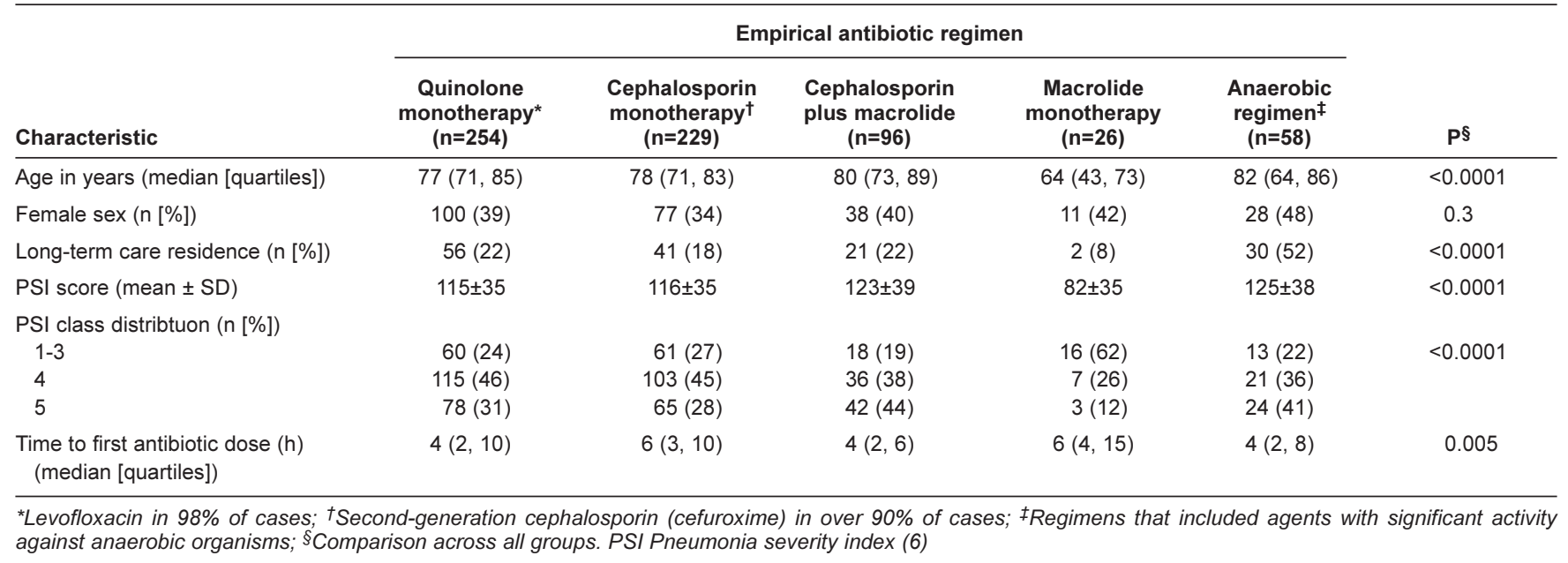

TABLE 4

Treatment and outcomes classified by empirical antibiotic therapy

\begin{tabular}{|c|c|c|c|c|c|c|}
\hline \multirow[b]{2}{*}{ Characteristic } & \multicolumn{5}{|c|}{ Empirical antibiotic regimen } & \multirow[b]{2}{*}{$\mathbf{P} \S$} \\
\hline & $\begin{array}{c}\text { Quinolone } \\
\text { monotherapy* } \\
(n=254)\end{array}$ & $\begin{array}{l}\text { Cephalosporin } \\
\text { monotherapy } \\
\quad(n=229)\end{array}$ & $\begin{array}{l}\text { Cephalosporin } \\
\text { plus macrolide } \\
\qquad(n=96)\end{array}$ & $\begin{array}{c}\text { Macrolide } \\
\text { monotherapy } \\
(n=26)\end{array}$ & $\begin{array}{c}\text { Anaerobic } \\
\text { regimen }^{\ddagger} \\
(n=58)\end{array}$ & \\
\hline $\begin{array}{l}\text { Duration of intravenous therapy in days } \\
\text { (median [quartiles]) }\end{array}$ & $1(0,2)$ & $4(3,5)$ & $5(3,6)$ & $1(0,2)$ & $5(3,8)$ & $<0.0001$ \\
\hline Antibiotic cost (median [range]) & $\begin{array}{c}\$ 49.65 \\
(\$ 24.00 \text { to } \$ 79.00)\end{array}$ & $\begin{array}{c}\$ 72.12 \\
(\$ 43.14 \text { to } \$ 104.28)\end{array}$ & $\begin{array}{c}\$ 156.96 \\
(\$ 98.08 \text { to } \$ 256.58)\end{array}$ & $\begin{array}{c}\$ 27.02 \\
(\$ 13.40 \text { to } \$ 46.91)\end{array}$ & $\begin{array}{c}\$ 176.56 \\
(\$ 98.01 \text { to } \$ 288.48)\end{array}$ & $<0.0001$ \\
\hline Length of stay in days (median [quartiles]) & $7(4,10)$ & $7(5,10)$ & $8(5,12)$ & $6(4,9)$ & $9(5,12)$ & 0.02 \\
\hline Mortality (n [\%]) & $17(7)$ & $12(5)$ & $17(18)$ & $1(4)$ & $14(24)$ & $<0.0001$ \\
\hline \multicolumn{7}{|l|}{ Total number antibiotics (n [\%]) } \\
\hline 1 & $175(69)$ & $159(69)$ & 0 & $10(38)$ & 0 & $<0.0001$ \\
\hline 2 & $58(23)$ & $50(22)$ & $42(44)$ & $10(38)$ & $21(36)$ & \\
\hline$\geq 3$ & $21(8)$ & $20(9)$ & $54(56)$ & $6(24)$ & $37(64)$ & \\
\hline
\end{tabular}

*Levofloxacin in $98 \%$ of cases; †Second-generation cephalosporin (cefuroxime) in over $90 \%$ of cases; $¥$ Regimens that included agents with significant activity against anaerobic organisms; §Comparison across all groups

TABLE 5

Multivariable analysis classified by empirical antibiotic therapy

\begin{tabular}{|c|c|c|c|c|c|}
\hline \multirow[b]{2}{*}{ Characteristic } & \multicolumn{5}{|c|}{ Empirical antibiotic regimen } \\
\hline & $\begin{array}{l}\text { Quinolone } \\
\text { monotherapy* } \\
(n=254)\end{array}$ & $\begin{array}{l}\text { Cephalosporin } \\
\text { monotherapy } \\
\quad(n=229)\end{array}$ & $\begin{array}{l}\text { Cephalosporin } \\
\text { plus macrolide } \\
\qquad(n=96)\end{array}$ & $\begin{array}{l}\text { Macrolide } \\
\text { monotherapy } \\
(n=26)\end{array}$ & $\begin{array}{l}\text { Anaerobic } \\
\text { regimen } \\
(n=58)\end{array}$ \\
\hline Mortality (odds ratio $[95 \% \mathrm{Cl}]$ ) & NS & Reference & $\begin{array}{l}2.7(1.2 \text { to } 6.4) \\
\quad P=0.02\end{array}$ & NS & $\begin{array}{l}2.7(1.2 \text { to } 6.5) \\
\quad P=0.001\end{array}$ \\
\hline Difference in length of stay in days $(95 \% \mathrm{Cl})$ & NS & Reference & NS & $\begin{array}{c}-2.4(-0.6 \text { to }-3.8) \\
P=0.01\end{array}$ & NS \\
\hline $\begin{array}{l}\text { Difference in duration of intravenous therapy } \\
\text { in days }(95 \% \mathrm{Cl})\end{array}$ & $\begin{array}{c}-2.3(-2.0 \text { to }-2.5) \\
P<0.0001\end{array}$ & Reference & $\begin{array}{l}1.1(0.3 \text { to } 2.0) \\
\qquad P=0.005\end{array}$ & $\begin{array}{c}-2.6(-1.9 \text { to }-3.1) \\
P<0.0001\end{array}$ & NS \\
\hline Difference in antibiotic cost $(95 \% \mathrm{Cl})$ & $\begin{array}{c}-\$ 19.19 \\
(-\$ 11.41 \text { to }-\$ 25.85) \\
P<0.0001\end{array}$ & Reference & $\begin{array}{c}\$ 91.35 \\
(\$ 61.42 \text { to } \$ 128.33) \\
P<0.0001\end{array}$ & $\begin{array}{c}-\$ 43.71 \\
(-\$ 32.58 \text { to }-\$ 51.06) \\
P<0.0001\end{array}$ & $\begin{array}{c}\$ 64.76 \\
(\$ 34.58 \text { to } \$ 104.06) \\
P<0.0001\end{array}$ \\
\hline
\end{tabular}

Outcomes compared with cephalosporin monotherapy cohort as reference group. *Levofloxacin in $98 \%$ of cases; ${ }^{\dagger}$ Second-generation cephalosporin (cefuroxime) in over $90 \%$ of cases; ${ }^{\ddagger}$ Regimens that included agents with significant activity against anaerobic organisms. NS Not significant 
endorsement of the CAP guidelines, which were incorporated into antimicrobial handbooks distributed among the house staff and attending staff. Feagan et al (26) recently reported rates of CAP guideline adherence in 20 Canadian hospitals. They found an average adherence rate of $80 \%$, with a range of $48 \%$ to $100 \%$. Our results compare favourably and would place our institution in the 80th percentile of this group.

We were unable to detect an association between guideline adherence and mortality or LOS. The apparent lack of association could be due to a true lack of benefit from guideline adherence, inadequate power to detect a difference or a systematic difference between guideline-adherent and guideline-discordant cases not accounted for in the multivariable analysis. In the case of mortality, inadequate power is particularly likely given the relatively small number of patients reaching the end point and the relatively small number of cases not treated according to guidelines. Analyzing all guideline-adherent cases versus all guideline-discordant cases together, regardless of era, would have increased study power. This was not done because of significant differences between guideline versions. Given the older age and higher PSI score in guideline-adherent cases, it is unlikely that deviation from guidelines was random. Although we controlled for PSI and study site, there may have been other important prognostic factors that were imbalanced between groups. Regarding LOS, we also controlled for comorbid illness and long-term care (not significant), but indexes of comorbidity severity were unavailable. There was a shorter duration of IV antibiotic therapy in guideline-adherent cases in the recent era. Also, recent cohort guideline-adherent cases had a shorter duration of IV antibiotic therapy than early cohort guidelineadherent cases, which is explained by the use of levofloxacin and its associated rapid conversion to oral therapy.

There are several noteworthy observations regarding the use of specific antibiotics. The choice of antibiotic therapy was associated with illness severity. There was progressively increasing severity, measured by the PSI, in cases treated with macrolide monotherapy, cephalosporin or levofloxacin monotherapy, cephalosporin plus a macrolide and antianaerobe agents. Empirical treatment with antianaerobe agents or cephalosporin plus a macrolide was associated with higher mortality (odds ratio 2.7 for both), despite controlling for PSI score. These data provide an interesting comparison with those of Gleason et al (21). Similar to our experience of increased mortality in patients treated with antianaerobe agents, Gleason et al observed higher mortality in patients treated with beta-lactam/beta-lactam inhibitor combinations. Also, Mortensen et al (27) recently reported aspiration pneumonia as an independent risk factor for mortality in CAP, with a hazard ratio of 3.1, which is a risk magnitude similar to what we observed in patients treated with anaerobic coverage. In contrast to our experience regarding cephalosporin and macrolide combination therapy, Gleason et al observed lower mortality in patients receiving this regimen. The latter observation was pivotal in supporting the belief that atypical agents are important for patients with CAP. This belief was reflected in the IDSA CAP guidelines published in 2000, when the addition of a macrolide was first made mandatory (16).

The association that we observed between certain antibiotic combinations and mortality may relate to effects of the antimi- crobials themselves (inferior antibacterial effect or increased toxicity) or the presence of an unknown confounder, a particular problem in any study that is nonrandomized. Given the higher illness severity, as measured by the PSI, in patients receiving the 'high risk' antibiotic combinations, it is likely that other confounding factors are the cause. In the case of treatment with antianaerobe agents, the clinical suspicion of aspiration pneumonia is likely a powerful risk factor for mortality in CAP and should be considered in CAP mortality risk stratification. An analogous clinical impression of increased illness severity, above and beyond that captured by the PSI, may have been present in patients treated with the combination of cephalosporin and a macrolide, which may explain the increased mortality in this group. Similarly, we suspect that the association between macrolide monotherapy and shorter LOS could be due to an unmeasured confounder. The nonrandomized nature of this study is an important limitation in this regard, making it impossible to rule out the presence of important confounders.

Limitations of the PSI may be related to either intrinsically poor accuracy or inadequate transportability. Given the excellent performance of the model in the validation set of Fine et al (6), we suspect that the PSI is not intrinsically inaccurate, but rather that it is not readily transportable. In other words, one may not necessarily expect it to perform as well in other geographic or temporal settings, or in samples with different case ascertainment methods. Suboptimal transportability was observed by Flanders et al (28), who recommended recalibration of the PSI for its application in other settings. Poor transportability may occur due to the presence of a different spectrum of disease severity in a new population or underfitting (the omission of an important prognostic variable that is distributed differently in the new setting than in the original setting) (29). One example is the clinical impression of macroaspiration discussed above, which is a strong independent predictor not included in the PSI. In addition, difficult to quantify yet clinically important prognostic factors, such as a clinician's overall impression of illness severity, may also be relevant. Prospective study may be helpful in further elucidating unmeasured important confounders.

Studying clinical outcomes in patients treated with levofloxacin did not identify any significant differences in mortality or LOS, although there was a significantly shorter duration of IV therapy (by 2.3 days, $\mathrm{P}<0.0001$ ) and significantly lower drug costs (by $\$ 19.19, \mathrm{P}<0.0001$ ). Patients treated with empirical levofloxacin also tended to have simpler antibiotic regimens, with fewer total agents. The findings of effectiveness, less expense and simpler antibiotic regimens support the pragmatic recommendation of the recent CAP guidelines regarding the use of RQ monotherapy in patients hospitalized with moderately severe CAP.

\section{CONCLUSIONS}

The present study of inpatient therapy of CAP identified high rates of guideline compliance, despite a change in guidelines during the study period. The use of recent empirical treatment guidelines for CAP, including RQs (levofloxacin), was associated with favourable outcomes, lower drug costs and simpler antibiotic regimens. The association between mortality and certain empirical antibiotic combinations suggests that the PSI 
provides incomplete prognostic information and that further prospective study is needed to identify other potentially important prognostic factors.

ACKNOWLEDGEMENTS: The authors thank Mr Leslie Lee Pack for assistance with database design and maintenance. Dr Marras is a Canadian Thoracic Society and Canadian Institutes of Health Research post-doctoral fellow, and also receives support from the University of Toronto, Clinician Scientist Program. This study was supported in part by an unrestricted grant from Janssen-Ortho Incorporated. The sponsor played no role in study design, data collection, analysis, manuscript preparation or the decision to publish the work.

\section{REFERENCES}

1. Jokinen C, Heiskanen L, Juvonen H, et al. Incidence of communityacquired pneumonia in the population of four municipalities in eastern Finland. Am J Epidemiol 1993;137:977-88.

2. Foy HM, Cooney MK, Allan I, Kenny GE. Rates of pneumonia during influenza epidemics in Seattle, 1964 to 1975. JAMA 1979;241:253-8.

3. Niederman MS, McCombs JS, Unger AN, Kumar A, Popovian R. The cost of treating community-acquired pneumonia. Clin Ther 1998;20:820-37.

4. LaForce FM. Community-acquired lower respiratory tract: Prevention and cost-control strategies. Am J Med 1985;78:52-7.

5. Helwig D. Major cost reductions reported in Canadian pneumonia study. eCMAJ Today, February 9, 2000. < http://collection.nlc-bnc.ca/100/ 201/300/cdn_medical_association/cmaj/cmaj_today/2000/02_09.htm> (Version current at February 27, 2004).

6. Fine MJ, Auble TE, Yealy DM, et al. A prediction rule to identify low-risk patients with community-acquired pneumonia. N Engl J Med 1997;336:243-50.

7. Chow CW, Lee-Pack LR, Senathiragah N, Rawji M, Chan M, Chan CK. Community acquired, nursing home acquired and hospital acquired pneumonia: A five year review of the clinical, bacteriological and radiological characteristics. Can J Infect Dis 1995;6:317-25.

8. Marras TK, Chan CK. Use of guidelines in treating communityacquired pneumonia. Chest 1998;113:1689-94.

9. Woodhead MA, MacFarlane JT. Comparative clinical laboratory features on Legionella with pneumococcal and Mycoplasma pneumonias. Br J Dis Chest 1987;81:133-9.

10. Farr BM, Kaiser DL, Harrison BD, Connolly CK. Prediction of microbial etiology at admission to hospital for pneumonia from the presenting clinical features. Thorax 1989;44:1031-5.

11. Chan CHS, Cohen M, Pang J. A prospective study of communityacquired pneumonia in Hong Kong. Chest 1992;101:442-6.

12. MacFarlane JT, Miller AC, Roderick Smith WH, Morris AH, Rose DH. Comparative radiographic features of community-acquired Legionnaires' disease, pneumococcal pneumonia, Mycoplasma pneumonia, and psittacosis. Thorax 1984;39:28-33.
13. Tew J, Calenoff L, Berlin BS. Bacterial or nonbacterial pneumonia: Accuracy of radiographic diagnosis. Radiology 1977;124:607-12.

14. Guidelines for the management of community-acquired pneumonia in adults admitted to hospital. The British Thoracic Society. Br J Hosp Med 1993;49:346-50.

15. Mandell LA, Marrie TJ, Grossman RF, Chow AW, Hyland RH. Canadian guidelines for the initial management of communityacquired pneumonia: An evidence-based update by the Canadian Infectious Diseases Society and the Canadian Thoracic Society. Clin Infect Dis 2000;31:383-421.

16. Bartlett JG, Dowell SF, Mandell LA, File TM, Musher DM, Fine MJ. Practice guidelines for the management of community-acquired pneumonia in adults. Clin Infect Dis 2000;31:347-82.

17. ERS Task Force Report. Guidelines for management of adult community-acquired lower respiratory tract infections. European Respiratory Society. Eur Respir J 1998;11:986-91.

18. Niederman MS, Mandell LA, Anzueto A, et al. American Thoracic Society. Guidelines for the management of adults with community-acquired pneumonia. Diagnosis, assessment of severity, antimicrobial therapy, and prevention. Am J Respir Crit Care Med 2001;163:1730-54.

19. Heffelfinger JD, Dowell SF, Jorgensen JH, et al. Management of community-acquired pneumonia in the era of pneumococcal resistance. Arch Intern Med 2000;160:1399-408.

20. Gleason PP, Kapoor WN, Stone RA, et al. Medical outcomes and antimicrobial costs with the use of the American Thoracic Society guidelines for outpatients with community-acquired pneumonia. JAMA 1997;278:32-9.

21. Gleason PP, Meehan TP, Fine JM, Galusha DH, Fine MJ. Associations between initial antimicrobial therapy and medical outcomes for hospitalized elderly patients with pneumonia. Arch Intern Med 1999;159:2562-72.

22. Marrie TJ, Lau CY, Wheeler SL, Wong CJ, Vandervoort MJ, Feagan BG. A controlled trial of a critical pathway for treatment of community-acquired pneumonia. JAMA 2000;283:749-55.

23. Mandell LA, Niederman MS, The Canadian Community-Acquired Pneumonia Consensus Group. Antimicrobial treatment of community acquired pneumonia in adults: A conference report. Can J Infect Dis 1993;4:25-8.

24. Bartlett JG, Breiman RF, Mandell LA, File TM Jr. Community-acquired pneumonia in adults: Guidelines for management. The Infectious Diseases Society of America. Clin Infect Dis 1998;26:811-38.

25. Marrie TJ, Durant H, Yates L. Community-acquired pneumonia requiring hospitalization: 5-year prospective study. Rev Infect Dis 1989;11:586-99.

26. Feagan BG, Marrie TJ, Lau CY, Wheeler SL, Wong CJ, Vandervoort MK. Treatment and outcomes of community-acquired pneumonia at Canadian hospitals. CMAJ 2000;162:1415-20.

27. Mortensen EM, Coley CM, Singer DE, et al. Causes of death for patients with community-acquired pneumonia. Arch Intern Med 2002;162:1059-64.

28. Flanders WD, Tucker G, Krishnadasan A, Martin D, Honig E, McClellan WM. Validation of the pneumonia severity index: Importance of studyspecific recalibration. J Gen Intern Med 1999;14:333-40.

29. Justice AC, Covinsky KE, Berlin JA. Assessing the generalizability of prognostic information. Ann Intern Med 1999;130:515-24. 


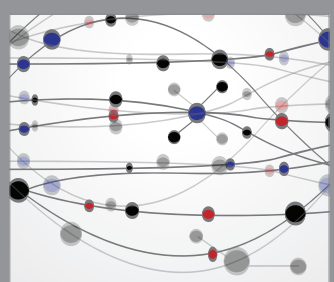

The Scientific World Journal
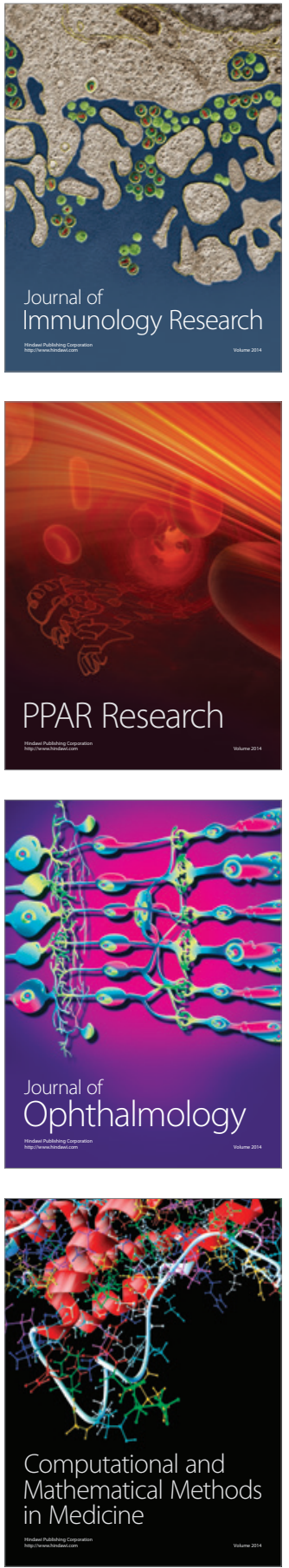

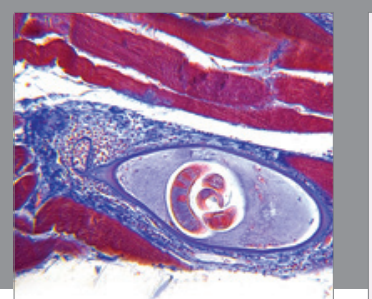

Gastroenterology Research and Practice

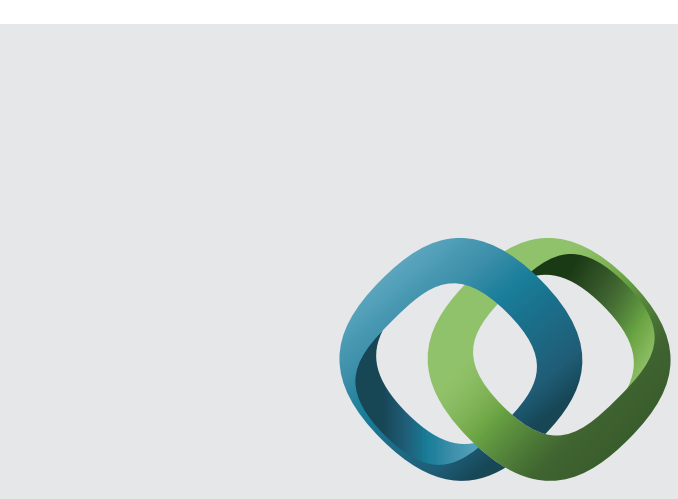

\section{Hindawi}

Submit your manuscripts at

http://www.hindawi.com
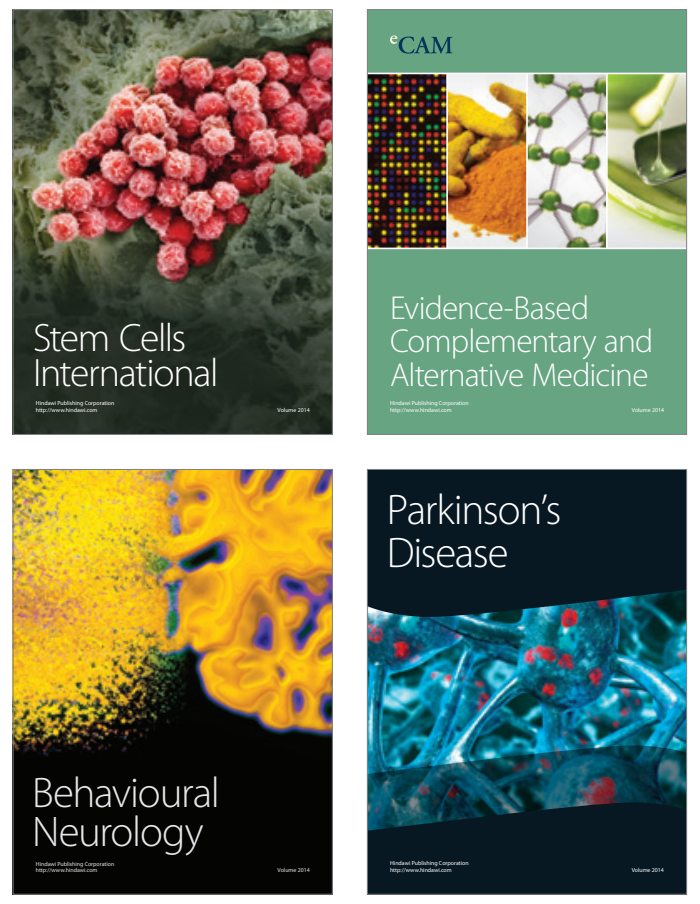
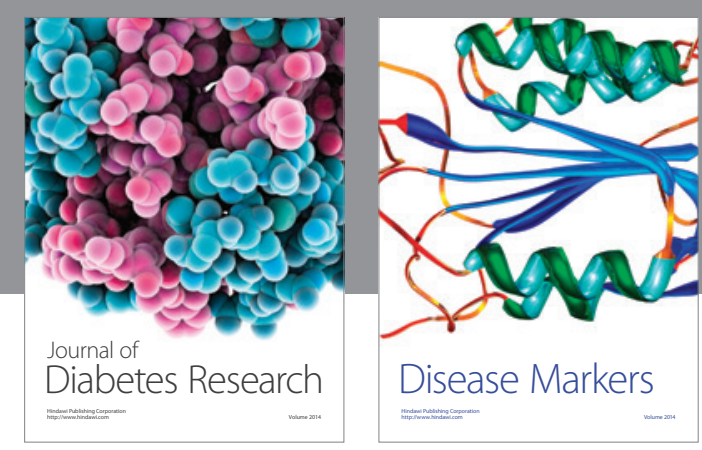

Disease Markers
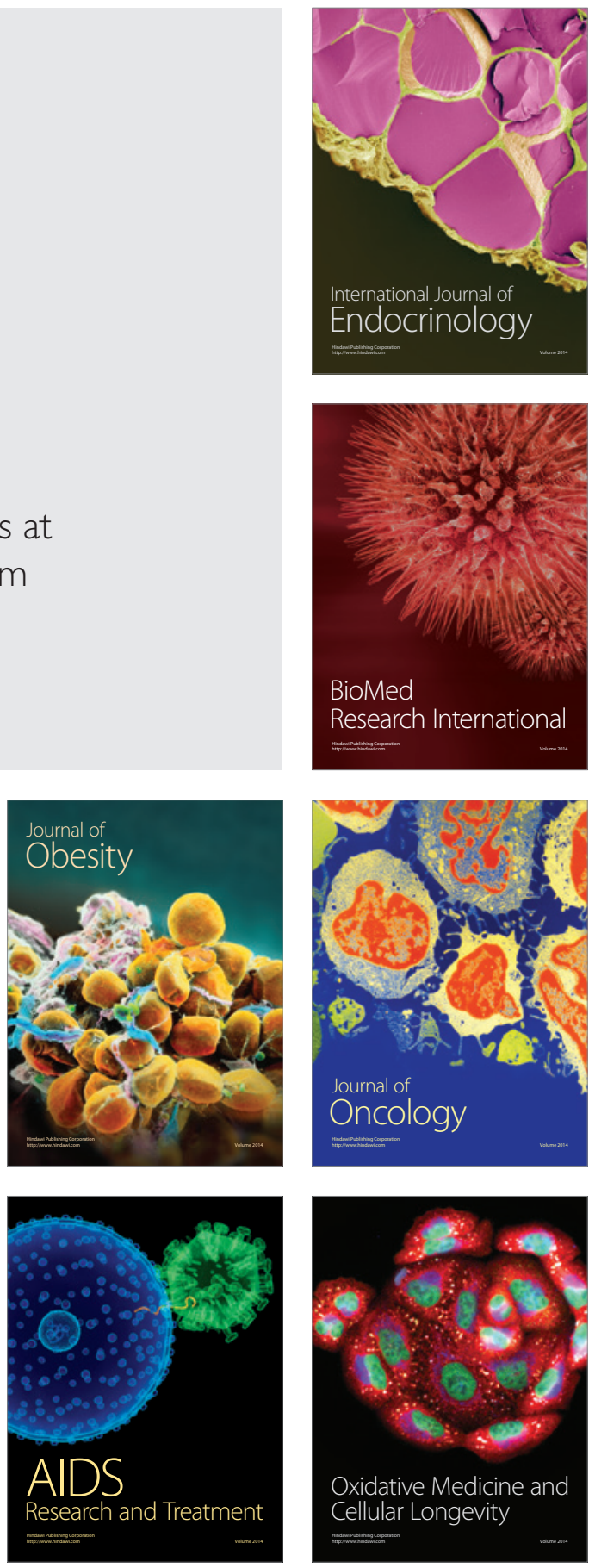